\title{
A Retrospective, Single-Center Comparative Cost Analysis of OnabotulinumtoxinA and AbobotulinumtoxinA for Cervical Dystonia Treatment
}

\author{
Richard M. Trosch, MD; Alicia C. Shillington, PhD; Marci L. English, MPH; and Dominic Marchese, RPh
}

\begin{abstract}
BACKGROUND: Chemodenervation with botulinum neurotoxin (BoNT) is recommended as first-line treatment for the management of cervical dystonia. The choice of BoNT for treatment is subject to the consideration of several factors, including cost.

OBJECTIVE: To compare the costs incurred by patients and payers for onabotulinumtoxinA (ONA) or abobotulinumtoxinA $(A B 0)$ for the treatment of cervical dystonia.

METHODS: We conducted a retrospective, noninterventional closed cohort study of cervical dystonia patients within a single U.S. private neurological practice. Patient and payer incurred costs from medical billing records for patients satisfying inclusion and exclusion criteria treated from November 1, 2009, through January 1, 2013, were de-identified and included in the analysis. Forty-seven patients initially treated with at least 3 consecutive cycles of ONA, followed by at least 3 consecutive cycles of $A B O$ were included, representing 282 injection cycles available for analysis. Patients were required to have had a positive response to treatment with both agents and no concomitant treatment with BoNT for any other condition during the analysis period. The analysis compared the primary endpoint of median overall payer and patient incurred costs reimbursed to the clinic under each treatment regimen. For the purposes of this cost analysis, comparable clinical outcomes on both therapies was assumed.
\end{abstract}

RESULTS: Switching from ONA to ABO resulted in an overall incurred reimbursement cost savings for payers and patients. Median costs per injection cycle for ONA were $\$ 1,925(\$ 0-\$ 2,814)$ compared with $\$ 1,214$ (\$229-

$\$ 2,899 ; P<0.0001)$ for $\mathrm{AB} 0$, representing an approximate $37 \%$ reduction in incurred reimbursement costs inclusive of toxin and procedure. Overall toxin reimbursement costs, patient out-of-pocket toxin costs, and the cost of unavoidable waste were also lower when patients were treated with $A B 0$.

CONCLUSIONS: For patients treated for cervical dystonia, switching from ONA to $A B O$ resulted in payer and patient reimbursement cost reductions in a single U.S. private practice with outcomes assumed to be similar.

J Manag Care Spec Pharm. 2015;21(10):854-60

Copyright $\odot 2015$, Academy of Managed Care Pharmacy. All rights reserved.

\section{What is already known about this subject}

Abobotulinumtoxin A and onabotulinumtoxinA are effective in the management of cervical dystonia (CD).

$\mathrm{CD}$ is a disease that may require lifelong, frequent treatments to maintain control of CD symptoms and functional status.

In patients with $\mathrm{CD}$, botulinum toxins can improve dystonic posture, range of motion, tremor, and pain.

\section{What this study adds}

This retrospective study demonstrated a reimbursement cost difference when utilizing abobotulinumtoxinA for the treatment of CD in single practice in the United States

Switching from onabotulinumtoxinA to abobotulinumtoxinA may help reduce overall health care spending related to the treatment of CD.

Patients with copays or coinsurance may have out-of-pocket cost reductions after switching from onabotulinumtoxinA to abobotulinumtoxinA.

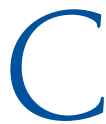

ervical dystonia (CD), also known as spasmodic torticollis, is the most common form of adult-onset focal dystonia, with a reported U.S. prevalence in 2007 of 390 per $100,000 .{ }^{1}$ CD symptoms typically begin to emerge in middle age, with an average age of onset of 41 years and a higher prevalence in women. ${ }^{2}$ There are 4 types of $\mathrm{CD}$, depending on which of the 52 different neck muscles are contributing to the abnormal head rotation and posture: torticollis, anterocollis, laterocollis, and retrocollis. Most patients present with a combination of these forms. ${ }^{3}$ Although remission can occur, it is rare, and most patients require decades of care. ${ }^{4,5}$ Therapeutic options for CD include oral medications, botulinum neurotoxin (BoNT) injections, and surgical procedures of selective denervation or deep brain stimulation surgery. ${ }^{6}$ Currently, BoNT chemodenervation therapy is the standard of care for the treatment of $\mathrm{CD}$. All BoNT products have received the same Level A recommendation from the American Academy of Neurology Technology and Therapeutics Assessment. Surgical procedures and oral medications are generally reserved for patients failing to respond to BoNT.7,8

BoNT is a neurotoxin isolated from the Clostridium botulinum bacteria and is considered the most lethal naturally produced substance. However, when injected locally in minute doses, BoNT inhibits the release of acetylcholine at the neuromuscular junction causing a temporary paralysis and weakening of the affected muscle that lasts up to 3-4 months. ${ }^{9}$ Since U.S. approval, BoNTs have been used by multiple therapeutic specialties including neurology, gastroenterology, urology, pain management, and dermatology. Rarely do specialty products 
cross multiple therapeutic areas, have so many approved indications, and have reimbursement for use.

The safety and efficacy of BoNT serotype A (BoNT-A) injections for the treatment of $\mathrm{CD}$ has been extensively investigated, with all U.S. commercially available products receiving approval from the U.S. Food and Drug Administration (FDA) for CD indication. ${ }^{10}$ Botox (onabotulinumtoxinA [ONA]) was approved in 1989 and was the first commercially available BoNT-A. Dysport (abobotulinumtoxinA [ABO]) was approved in 2009.11,12 All BoNT-A products contain an identical $150 \mathrm{kDa}$ active neurotoxin core, molecular amino acid sequence, intracellular mechanism of action of inhibiting acetylcholine release from the peripheral cholinergic nerve terminal, and the same pharmacodynamic effect of chemodenervation. However, the manufacturing process for each is proprietary, potentially affecting the pharmacological and biochemical characteristics of each product. In addition, each manufacturer uses a unique assay to quantitate potency; therefore, units of biological activity cannot be compared nor converted between BoNT products. ${ }^{13}$ The clinical relevance of these differences is not known. Although the units of biological activity are not equivalent, multiple double-blind, randomized, cross-over, noninferiority, and/or retrospective clinical studies assessing health outcomes have been conducted demonstrating comparable clinical safety and efficacy between ONA and ABO in the treatment of $\mathrm{CD} \cdot{ }^{14-17}$ These studies have suggested an appropriate conversion factor of less than 3 and possibly as low as 1.7 in CD.

While BoNT therapy is effective in improving the symptoms of $C D$, patients often report dissatisfaction with their therapy and discontinue treatment. ${ }^{18}$ A recent international survey of CD patients reported that $56 \%$ were fairly or very satisfied; $20 \%$ were neither satisfied nor dissatisfied; and 24\% were completely or fairly dissatisfied with their response to BoNT therapy. ${ }^{19}$ Since the approval of $\mathrm{ABO}$, the Parkinson's and Movement Disorder Center implemented a standard practice of providing $C D$ patients with an option at each visit of either continued treatment with ONA or switching to ABO. Having been presented with a new BoNT option, many patients chose to switch from ONA to $\mathrm{ABO}$, allowing a comparison of the payer and patient reimbursement costs of using ONA or $A B O$ for $\mathrm{CD}$ before and after a switch.

This retrospective, noninterventional, closed cohort study was conducted to examine differences in real-world cost incurred by payers and patients, while receiving $\mathrm{ABO}$ and then switching to ONA, for the treatment of CD with assumed comparable clinical outcomes for both therapies. Real-world costs to the payer and to the patient include the incurred reimbursement cost of the procedure, units of product injected, and units of unavoidable wastage paid to the clinic. BoNT is supplied as a single-use vial, and therapy is often individualized, which results in unused units from those vials being billed and paid for by the payer and the patient.

\section{Methods}

\section{Study Design and Patient Population}

This was a noninterventional, retrospective, observational, cost-minimization closed cohort study conducted at a single clinical site in the United States. The primary objective was to retrospectively evaluate the impact on reimbursement costs incurred by patients and payers who voluntarily switched from ONA to ABO for the treatment of $\mathrm{CD}$ after $\mathrm{ABO}$ became commercially available in the United States. For this analysis, costs were defined as (a) reimbursement costs for drug and administration procedures paid to the clinic as incurred by the payer and (b) patient out-of-pocket (OOP) costs incurred and paid to the clinic for providing and administering the toxin. Patient OOP costs included any copay or coinsurance incurred by the patient for the chemodenervation procedure and the BoNT. Costs did not include costs incurred by the clinic to acquire the BoNT nor the overhead costs to provide the service.

The study population was derived from approximately 2,500 neurological patients treated at the Michigan clinical practice that specializes in the treatment of movement disorders. Medical records of patients with a diagnosis of idiopathic CD (International Classification of Diseases, Ninth Revision, Clinical Modification [ICD-9-CM] code 333.83 for spasmodic torticollis) were screened for history of treatment with BoNT, and 110 patients were identified. ${ }^{20}$ From these, patients were selected who were aged $>18$ years, had received 3 consecutive injection cycles of ONA with a subsequent change to $\mathrm{ABO}$ for 3 consecutive cycles with no interruption in treatment and with $>12$ weeks between injection cycles, and demonstrated a positive patient response on symptom control after the 3 cycles of ONA and the 3 cycles of ABO. Three cycles were selected, since the investigator empirically established that patients tend to be stabilized after 2 treatment cycles of dose adjustments and identifying appropriate affected muscles for injection. Therefore, it was assumed that after 3 treatment cycles of each product patients would be at a stable dose. A minimum standard starting dose of $\mathrm{ABO}$ for patients switched from ONA was determined empirically by the investigator based on previous clinical experience following $\mathrm{ABO}$ commercial availability in the United States. The physician elected to start all patients who switched from ONA to $A B O$ at a dose of 2 Units (U) ABO to $1 \mathrm{U}$ ONA, with subsequent $\mathrm{ABO}$ doses adjusted depending on clinical response.

Standard of care at the clinic included querying patients regarding their responses to the previous injection cycle. Patient-reported outcome rating scales are commonly used in movement disorders to evaluate a patient response to a therapeutic intervention. ${ }^{21}$ The scale in use included a 4-point Likert scale consisting of "none, mild, moderate, or marked." To establish symptom control and ensure that patients with similar health outcomes were included in this cost analysis, patients 


\begin{tabular}{|c|c|}
\hline \multicolumn{2}{|c|}{$\begin{array}{l}\text { Patient Demographics and } \\
\text { Characteristics }\end{array}$} \\
\hline Total patients, $\mathrm{n}$ & 47 \\
\hline Male/female, n (\%) & $14 / 33(30.0 / 70.0)$ \\
\hline Age at date of switch, years, mean \pm SD & $59.8 \pm 12$ \\
\hline Median (range) & $59.5(30.7-90.8)$ \\
\hline Years treated for CD in practice, mean (SD) & $\begin{array}{ll}7 & (5.2) \\
\end{array}$ \\
\hline \multicolumn{2}{|l|}{ Years treated for CD in practice, $\mathrm{n}(\%)$} \\
\hline$<1$ & $(8.5)$ \\
\hline $1-5$ & $(29.8)$ \\
\hline $6-10$ & $(31.9)$ \\
\hline$>10$ & $(29.8)$ \\
\hline
\end{tabular}

reporting no response were excluded. In addition, to ensure continuity of care, we evaluated the muscles injected at the final ONA injection series and last collected ABO injection series.

Patients were also excluded if they had not been treated with both ONA and ABO and had not had 3 consecutive cycles of ONA followed by 3 consecutive cycles of $\mathrm{ABO}$. Patients were excluded if they received concomitant treatment with any BoNT for reasons other than CD at any time during the ONA or $\mathrm{ABO}$ treatment cycles; if their patterns of ONA to $\mathrm{ABO}$ use did not follow a series of 3 consecutive injections of each product; or if they alternated between toxins. All patients within the practice satisfying the inclusion and exclusion criteria from November 1, 2009, through January 1, 2013, had their data de-identified and included in the analysis.

Cost outcomes were defined as total reimbursement costs incurred by payers and patients paid to the clinic for providing and administering the toxin. To determine this cost, data were extracted from medical billing records that included reimbursement corresponding to the Current Procedural Terminology (CPT) procedure code 64613 Chemodenervation of muscle(s) and neck muscle(s) and reimbursement corresponding to the Healthcare Common Procedure Coding System J Codes (J0586, injection abobotulinumtoxinA, 5 units and J0585, injection onabotulinumtoxinA, 1 unit). ${ }^{22}$ Actual reimbursement received from payers was used, since the reimbursement rate per CPT code and per billable J Code unit is established by each payer; thus, rates may vary depending on payer and patient individual health plans. Reimbursement cost associated with the chemodenervation procedure (CPT code 64613) remains the same regardless of which J Code is used; as such, we anticipated no significant differences in procedural reimbursement. Botulinum toxin products are supplied as a single dose vial, so unavoidable wastage of units may occur. For the analysis, we calculated unavoidable waste of units as an average across all patients.

\begin{tabular}{l|rr|rr}
\multicolumn{1}{c|}{ TABLE 2 Insurance Coverage at Each BoNT } \\
Injection Cycle
\end{tabular}

$a_{n}=$ injection cycles; insurance coverage may have changed cycle to cycle. bIncludes Medicare and commercial payers.

$A B O=$ abobotulinumtoxin $A ; B O N T=$ botulinum neurotoxin; $H M O=$ health maintenance organization; $O N A=$ onabotulinumtoxin $A ; P O S=$ point of service; $P P O=$ preferred provider organization .

\section{Statistical Analyses}

Patient demographics and disease characteristics were analyzed descriptively, including use of means, standard deviations (SDs), and relative frequencies for continuous and categorical data, respectively. Dose of toxin during ONA and ABO cycles was analyzed descriptively using means and SDs. Because equal efficacy is assumed in a cost minimization study, this study was not designed to determine effectiveness outcomes; however, patientreported clinical response was compared using a McNemar test for marginal homogeneity to verify no significant change in response between agents. For costs, we examined actual reimbursement costs incurred by patient and payer for the last 3 ONA injections prior to changing treatment to $\mathrm{ABO}$, compared with costs of the following $3 \mathrm{ABO}$ injections.

Since cost data are generally assumed to be skewed, we examined costs nonparametrically. Costs were described using medians and ranges and were compared using a Wilcoxon signed-ranked test to determine statistical significance. Dependent upon when a patient switched from ONA to $\mathrm{ABO}$, patients may have met their annual OOP maximum for either agent and had zero cost. A small subset may have received a BoNT sampled product. Therefore, we analyzed toxin reimbursement cost incurred by patients across all cycles and also only for those cycles with an OOP responsibility (i.e., toxin cost $\geq \$ 1)$.

\section{Standard Protocol Approvals, Registrations, and Patient Consent}

The New England Institutional Review Board provided exempt review for this research, since it involved de-identified data from existing records. Because this study was a retrospective evaluation of de-identified data, patient consent was waived.

\section{Results}

\section{Demographics and Patient Characteristics}

Forty-seven patients were identified for analysis, with 282 injection cycles administered-141 injection cycles available 


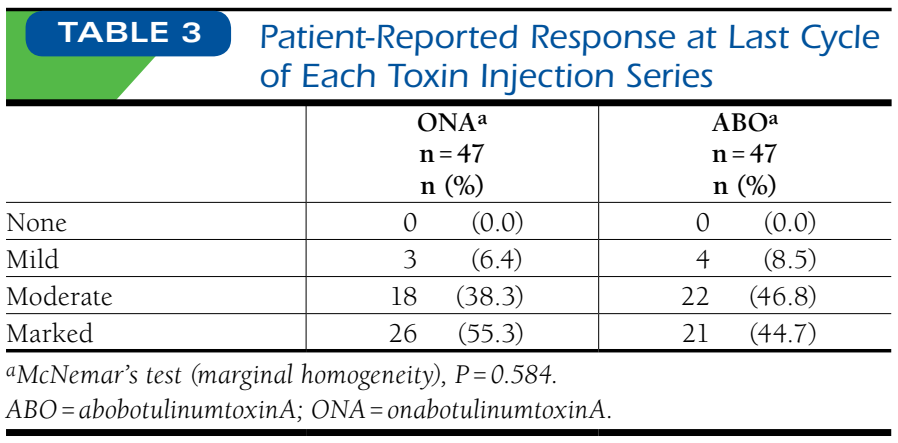

each for $\mathrm{ONA}$ and $\mathrm{ABO}$. The mean age of patients at the time of switch was $59.8(\mathrm{SD} \pm 12)$ years, and $70.2 \%$ of the patients were female. The mean duration of treatment for $\mathrm{CD}$ within the practice was 7 years, with $>60 \%$ of the patients treated for CD in the practice for more than 6 years (Table 1). Insurance types were analyzed by injection cycle in order to evaluate potential changes in insurance type between cycles. There were no significant changes to insurance types before and after switch or between cycles, with the exception of 6 individuals who, for 1 treatment cycle each, did not have insurance at the time of their ONA treatments. Medicare, Medicaid, and Blue Cross Blue Shield covered the majority of injection cycles for each ONA and $\mathrm{ABO}$ treatment series, $57.4 \%$ and $61.0 \%$, respectively (Table 2 ).

Although equal effectiveness among BoNT agents was assumed, patient-reported clinical response before and after the switch to $\mathrm{ABO}$ (the last patient-reported benefit following final ONA injection, after 3 consecutive ABO cycles) was assessed to ensure comparable response (Table 3). Mean (SD) days between injection cycles was not significantly different (99 [15] days for ONA and 101 [31] days for $\mathrm{ABO} ; \mathrm{P}=0.480$ ). Overall, the mean (SD) toxin dose injected to produce a positive response (any response other than "none") after 3 consecutive cycles was ONA 284 (62) U and ABO 552 (120) U, while maintaining a similar degree of improvement (Table 4). As supportive evidence of treatment pattern continuity, we evaluated the muscles injected at the final ONA and last collected ABO injections, which demonstrated no clinically meaningful difference.

\section{Reimbursement Cost Analyses: Patients and Payers}

Switching from ONA to ABO resulted in an overall reduction in total reimbursement costs for BoNT therapy incurred by patients and payers paid to the clinic. Median chemodenervation reimbursement amounts (given as median [range]) for toxin and procedure across all cycles incurred by patients and payers for the ONA injection series were \$1,925 (\$0$\$ 2,814)$ as compared with $\$ 1,214(\$ 229-\$ 2,899)$ for the ABO series $(P<0.0001$; Table 5$)$. Total reimbursement to the clinic for BoNT (minus procedure) accounted for the majority of expenditure and was significantly higher for ONA versus $\mathrm{ABO}$
TABLE 4 Toxin Units Injected at Each Cycle

\begin{tabular}{l|c|c}
\hline & $\begin{array}{c}\text { ONA } \\
\mathbf{n}=\mathbf{1 4 1} \\
\text { Mean (SD) }\end{array}$ & $\begin{array}{c}\text { ABO } \\
\mathbf{n}=\mathbf{1 4 1} \\
\text { Mean (SD) }\end{array}$ \\
\hline Cycle 1 & $280 \mathrm{U}(62)$ & $539 \mathrm{U}$ (116) \\
\hline Cycle 2 & $284 \mathrm{U}(59)$ & $557 \mathrm{U}(115)$ \\
\hline Cycle 3 & $289 \mathrm{U}(66)$ & $561 \mathrm{U}(130)$ \\
\hline All cycles & $284 \mathrm{U}(62)$ & $552 \mathrm{U}(120)$ \\
\hline
\end{tabular}

$A B O=$ abobotulinumtoxin $A ; O N A=$ onabotulinumtoxin $A ; S D=$ standard deviation; $U=$ units.

$(\$ 1,710[\$ 0-\$ 2,266]$ vs. $\$ 988$ [\$0-\$2,747]). Costs incurred for individual injection cycles also demonstrated lower median costs incurred by the patient and payer for $\mathrm{ABO}$ versus ONA. Procedure cost was modestly lower for $\mathrm{ABO}$ versus ONA, but this was not statistically significant.

To further investigate the reimbursement cost differences, we performed several additional analyses. When comparing just the payer reimbursement costs for BoNT (minus procedure costs), $\mathrm{ABO}$ demonstrated statistically significant savings, with ONA reimbursed at $\$ 1,596(\$ 0-\$ 2,660)$ versus ABO $\$ 925$ ( $\$ 0$ $\$ 2,577 ; P<0.0001)$. Patients had no OOP cost in 97 (68.8\%) of ONA injection cycles and 99 (70.2\%) of ABO injection cycles. To determine cost per cycle for patients with a copay or coinsurance, we examined patient-incurred cost per cycle excluding these cycles. For this subset, patients' median OOP costs were ONA \$285 (\$24-\$2,535) versus ABO \$181 (\$15-\$1,363). This represents a mean reduction of $37 \%$ in total reimbursement BoNT costs, excluding procedure costs (Table 6).

Unavoidable waste was examined on a unit basis. The average number of wastage units for $\mathrm{ONA}$ was $36 \mathrm{U}(\mathrm{SD} \pm 12)$ versus $82 \mathrm{U}(\mathrm{SD} \pm 44)$ for $\mathrm{ABO}$, with $P<0.001$. During the course of treatment, 6 ONA injection cycles and $2 \mathrm{ABO}$ injection cycles were performed with sampled product and not billed to the payer or patient. Median cost of waste, excluding cycles receiving samples not reimbursed, represented a lower median total cost of unavoidable waste for ABO \$148 (\$0$\$ 550)$ versus ONA $\$ 165(\$ 0-\$ 435 ; P<0.0001)$, despite more units wasted (Table 7).

\section{Discussion}

This retrospective study found substantial reimbursement cost reductions incurred by switching BoNT products from ONA to $\mathrm{ABO}$ for the treatment of $\mathrm{CD}$ primarily to the payer. Patients with copays or coinsurance had significant cost reductions, as well. The mean difference of approximately $37 \%$ in total reimbursement cost (procedure plus BoNT) of providing care was attributable primarily to lower costs of $\mathrm{ABO}$. Given that reimbursement costs associated with the chemodenervation procedure (CPT code 64613) are identical within payers regardless which BoNT is injected, it was observed that procedural 
A Retrospective, Single-Center Comparative Cost Analysis of

OnabotulinumtoxinA and AbobotulinumtoxinA for Cervical Dystonia Treatment

TABLE 5 Total Chemodenervation Costs Incurred by Patient and Payers: Toxin and Procedure Reimbursement ${ }^{2}$

\begin{tabular}{|c|c|c|c|c|}
\hline \multirow[b]{2}{*}{ Total toxin reimbursement per cycle } & \multicolumn{2}{|c|}{$\begin{array}{c}\text { ONA } \\
\mathrm{n}=141 \\
\text { Median (range) \$ }\end{array}$} & $\begin{array}{c}\mathrm{ABO} \\
n=141 \\
\text { Median (range) \$ }\end{array}$ & \multirow{5}{*}{$\frac{P \text { Value }}{<0.0001}$} \\
\hline & 1,710 & $(0-2,660)$ & $988 \quad(0-2,747)$ & \\
\hline Cycle 1 & 1,710 & $(0-2,538)$ & $987 \quad 458-2,747)$ & \\
\hline Cycle 2 & 1,710 & $(0-2,633)$ & $987 \quad(458-2,747)$ & \\
\hline Cycle 3 & 1,711 & $(0-2,660)$ & $1,000 \quad(240-1,680)$ & \\
\hline Total procedure reimbursement per cycle ${ }^{b}$ & 222 & $(0-450)$ & $208 \quad(117-369)$ & 0.0640 \\
\hline Total reimbursement per cycle, toxin and procedure & 1,925 & $(0-2,814)$ & $1,214 \quad(229-2,899)$ & $<0.0001$ \\
\hline
\end{tabular}

reimbursement costs were higher during the $\mathrm{ABO}$ treatment series, but to a degree not meaningful when considering total costs. Excluding the reimbursement cost of the procedure from the analysis, a mean reduction of $37 \%$ in reimbursed BoTN cost difference was observed between ONA and ABO.

During most cycles for ONA and $\mathrm{ABO}$, patients did not incur any OOP costs. This was equitably observed with both agents. Only when evaluating those cycles in which there was an OOP responsibility did $\mathrm{ABO}$ treatment reduce OOP for patients. This difference, however, may be attributed to the reduction of individual patient coinsurance responsibility, since the overall reimbursement rate was lower on a percentage basis for $\mathrm{ABO}$. We found greater mean units wasted per cycle with $\mathrm{ABO}$. However, because $\mathrm{ABO}$ per unit reimbursement costs were lower, the overall expense of wasted toxin was lower for $\mathrm{ABO}$.

Following the FDA approval of $\mathrm{ABO}$, the clinic began offering $C D$ patients the option of continuing treatment with their current BoNT products or switching to ABO. Some patients chose to continue using ONA, while others chose to switch to $\mathrm{ABO}$. Although nearly all of the patients who switched to ABO and completed 3 treatment cycles previously reported a mod- erate or marked improvement with ONA, they were willing to try an alternative product. Given the retrospective nature of this study, reasons for switching and not switching were not available to the investigators. Reasons for patient willingness to switch may be attributed to the findings by Gill et al. (2013), which reported that dissatisfaction and cost of current BoNT therapy were the main reasons for stopping therapy. ${ }^{18}$ Following the switch from $\mathrm{ONA}$ to $\mathrm{ABO}$, at each subsequent visit, patients were provided with the choice of continuing treatment with either ONA or ABO. Anecdotal experience in the clinic suggests that many patients may have not qualified for this study because of oscillation between ONA and ABO after their first injection series with $\mathrm{ABO}$. The reasons for switching toxins when offered, not switching, and oscillating between toxins are not systematically documented in a manner available for retrospective collection.

At each visit, patients were asked to provide a global rating of their responses to their prior injection series and their duration of benefit. We found no significant difference in patients' perceived benefits from $\mathrm{ONA}$ or $\mathrm{ABO}$, which suggests that these treatments were clinically comparable at the doses used.

\section{TABLE 6 Detailed Patient Out-of-Pocket and Payer Reimbursement Costs Incurred ${ }^{a}$}

\begin{tabular}{|c|c|c|c|}
\hline & $\begin{array}{c}\text { ONA } \\
\mathbf{n}=\mathbf{1 4 1} \\
\text { Median (range) \$ }\end{array}$ & $\begin{array}{c}\mathrm{ABO} \\
\mathrm{n}=141 \\
\text { Median (range) \$ }\end{array}$ & $P$ Value \\
\hline Patient OOP toxin cost per cycle, all cycles & $0 \quad(0-2,535)$ & $0 \quad(0-1,363)$ & 0.6340 \\
\hline Patient OOP toxin cost per cycle, all cycles with patient OOP coinsurance responsibilityb & $285 \quad(24-2,535)$ & $181 \quad(15-1,363)$ & $<0.0001$ \\
\hline Patient OOP injection procedure cost per cycle & $(0-338)$ & $(0-252)$ & 0.7410 \\
\hline Payer toxin reimbursement cost per cycle, all cycles & $1,596 \quad(0-2,660)$ & $925 \quad(0-2,577)$ & $<0.0001$ \\
\hline Payer toxin cost per cycle, all cycles with patient OOP coinsurance responsibilityb & $(0-2,130)$ & $(0-2,576)$ & $<0.0001$ \\
\hline Total payer reimbursement for injection procedure per cycle & $(0-360)$ & $(0-369)$ & 0.0400 \\
\hline
\end{tabular}




\section{A Retrospective, Single-Center Comparative Cost Analysis of OnabotulinumtoxinA and AbobotulinumtoxinA for Cervical Dystonia Treatment}

Since this study was intended to represent real-world clinical practice, several patients were included who were provided free samples of toxin, either ONA or $\mathrm{ABO}$, and the procedure at no cost. Inclusion of these patients in our cost analysis resulted in no significant impact on cost. A patient's final $\mathrm{ABO}$ dose may have been increased or reduced based on clinical response or adverse effects. The data demonstrated that the initial dose used was generally maintained throughout the third $\mathrm{ABO}$ injection cycle, and an overall maintenance of benefit was observed as measured by patient response. The mean dose of $\mathrm{ONA}$ and $\mathrm{ABO}$ at the last cycle visit per series was $284 \mathrm{U}$ and $552 \mathrm{U}$, respectively. Our results are similar to the study by Rystedt et al. (2012), which found that patients who switched from ONA to $\mathrm{ABO}$ maintained their $\mathrm{ABO}$ starting doses or slightly reduced that dose over a $>6$-year follow-up period. ${ }^{17}$ In addition, our results are consistent with the prescribing information for both products, which describe a median dose of 236 $\mathrm{U}$ of ONA and recommended starting dose of $500 \mathrm{U}$ of $\mathrm{ABO}$ for naive and non-naïve CD patients. Furthermore, a recent large, prospective study of $\mathrm{ABO}$ use in real-world clinical practice found a median dose of $200 \mathrm{U}$ for ONA and a median dose of $500 \mathrm{U}$ for $\mathrm{ABO} .^{23}$ Together, these findings provide clinicians with guidance regarding an appropriate starting point when switching patients between toxins.

Our findings have economic implications, since CD is a disease requiring lifelong, frequent treatments to maintain control of $\mathrm{CD}$ symptoms and maintain functional status..$^{24,25}$ Given that the onset of $\mathrm{CD}$ typically occurs in midlife, ${ }^{26}$ patients face decades of treatment at quarterly intervals. Compounded over a lifetime, using a less costly toxin could result in substantial cost savings for patients and insurers. Although not representative of each cycle for each series, for those cycles where patients incurred OOP, $\mathrm{ABO}$ resulted in reduced OOP for those cycles in which insurance did not provide 100\% reimbursement coverage.

BoNT products are supplied as single-use vials. The amount of toxin utilized per patient is often not a fixed dose, so unavoidable wastage may occur from a single vial or the opening of multiple vials. Unavoidable wastage is included in the total amount billed to the payer and patient and documented per patient chart as amount of units injected and amount of unavoidable wastage, if necessary. ${ }^{27,28} \mathrm{~A}$ switch to $\mathrm{ABO}$ also appears to have decreased overall toxin expense because of reductions in the reimbursement cost for unavoidable waste.

The data are based upon health insurance reimbursement cost data at the time services were rendered and do not reflect any increase in wholesale acquisition costs of ONA or $\mathrm{ABO}$ or the increase in reimbursement costs associated with a BoNT or procedural reimbursement cost increase. Our analysis suggests that treating a $\mathrm{CD}$ patient with $\mathrm{ABO}$ every 13 weeks could provide a projected median savings of $\$ 2,844$ over a 1 -year period.

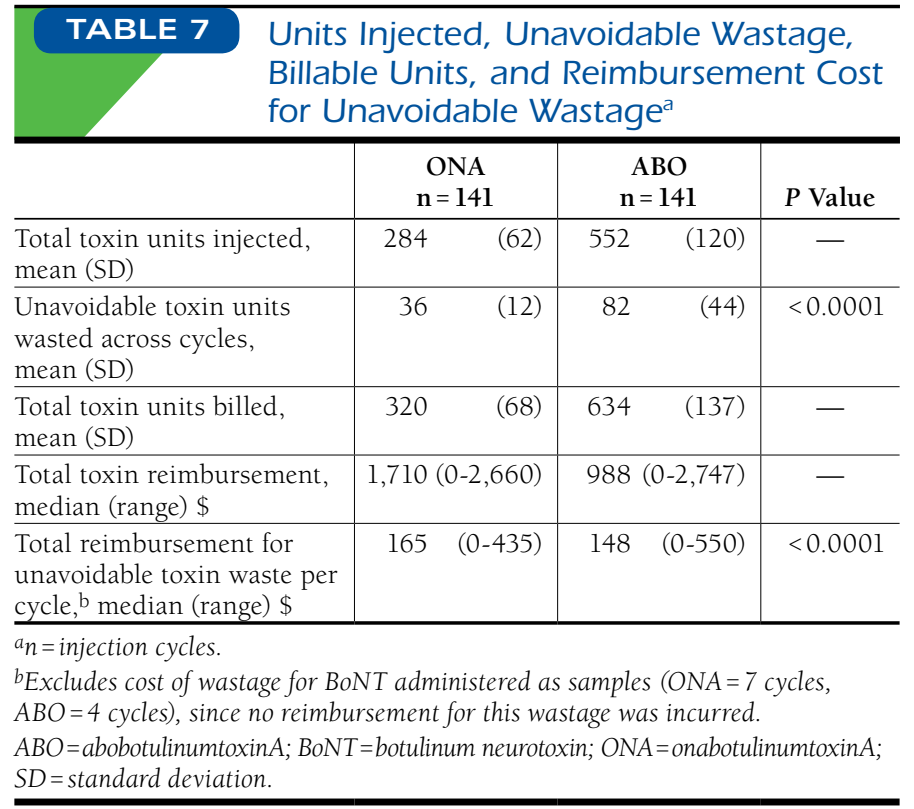

\section{Limitations}

This study has several methodological limitations. First, this is a retrospective analysis from a single clinical site. Additionally, the study population was derived from a U.S. neurology private practice, limiting the external validity of these results to practice settings where toxin costs or health care reimbursement may differ. The numbers were small $(n=47)$; replication in a larger population spread over more sites would be beneficial.

Second, because data were derived from routine clinical practice and collected from retrospective medical billing records, the reasons for patients not switching from ONA to ABO when offered were not documented or available for analysis. Furthermore, the study was not designed to assess the reimbursement and outcomes differences in those who switched and in those who remained on ONA. In addition, reimbursement cost data were not captured for those patients that elected to remain on or revert back to ONA. Third, during the retrospective review period, patient insurance may have changed, which would have impacted the total OOP expense for the procedure and product. Fourth, the study was not designed to capture acquisition costs associated with obtaining the botulinum toxin products nor the cost incurred by the clinic in performing the service. Finally, a subanalysis was not performed for each of the patient-reported responses categories.

\section{Conclusions}

Within the United States there is increasing pressure to provide affordable health care, particularly on physicians practicing in an accountable care organization environment, and to find less costly yet comparably efficacious treatment is both an ethical and economic imperative. This retrospective study identified a 


\section{A Retrospective, Single-Center Comparative Cost Analysis of OnabotulinumtoxinA and AbobotulinumtoxinA for Cervical Dystonia Treatment}

cost difference when a selected population switched treatment for $\mathrm{CD}$ from ONA to $\mathrm{ABO}$ in 1 U.S. clinical setting. The data derived from this pilot analysis should encourage additional research to explore cost differences and the drivers for these differences in other practice settings.

\section{Authors}

RICHARD M. TROSCH, MD, is Director, The Parkinson's and Movement Disorders Center, Farmington Hills, Michigan, and DOMINIC MARCHESE, RPh, is Medical Science Liaison, Ipsen Biopharmaceuticals, Basking Ridge, New Jersey. ALICIA C. SHILLINGTON, PhD, is Executive Vice President, and MARCI L. ENGLISH, MPH, was Director of Outcomes Research, EPI-Q, Oak Brook, Illinois.

AUTHOR CORRESPONDENCE: Richard M. Trosch, MD, The Parkinson's and Movement Disorders Center, 32255 Northwestern Hwy., Ste. 40, Farmington Hills, MI 48334. Tel.: 248.355.3875; E-mail: richardtrosch@comcast.net.

\section{DISCLOSURES}

This study was sponsored by Ipsen Biopharmaceuticals. Trosch has received personal compensation for speaking and/or consultative services from Ipsen and US WorldMeds, has previously served as a clinical investigator, and has had consulting agreements with Allergan. Shillington is a current employee of EPI-Q. English was an employee of EPI-Q during the time of this study. Marchese is an employee of Ipsen Biopharmaceuticals.

All authors had access to the data and contributed equally to the writing and revision of the manuscript.

\section{REFERENCES}

1. Jankovic J, Tsui J, Bergeron C. Prevalence of cervical dystonia and spasmodic torticollis in the United States general population. Parkinsonism Relat Disord. 2007;13(7):411-16.

2. Sex-related influences on the frequency and age of onset of primary dystonia. Epidemiologic Study of Dystonia in Europe (ESDE) Collaborative Group. Neurology. 1999;53(8):1871-73.

3. Stacy M. Epidemiology, clinical presentation, and diagnosis of cervical dystonia. Neurol Clin. 2008;26(Suppl 1):23-42.

4. Jahanshahi M, Marion MH, Marsden CD. Natural history of adult-onset idiopathic torticollis. Arch Neurol. 1990;47(5):548-52.

5. Friedman A, Fahn S. Spontaneous remissions in spasmodic torticollis. Neurology. 1986;36(3):398-400.

6. Jankovic J. Medical treatment of dystonia. Mov Disord. 2013;28(7):1001-12. 7. Simpson DM, Blitzer A, Brashear A, et al. Assessment: Botulinum neurotoxin for the treatment of movement disorders (an evidence-based review): report of the Therapeutics and Technology Assessment Subcommittee of the American Academy of Neurology. Neurology. 2008;70(19):1699-706.

8. Hallett M, Albanese A, Dressler D, et al. Evidence-based review and assessment of botulinum neurotoxin for the treatment of movement disorders. Toxicon. 2013;67:94-114.

9. Bell MS, Vermeulen LC, Sperling KB. Pharmacotherapy with botulinum toxin: harnessing nature's most potent neurotoxin. Pharmacotherapy. 2000;20(9):1079-91.
10. Gollump S. Neurotoxin therapy: a closer look at the four options. Practical Neurology. March/April 2011, pp. 27-33. Available at: http://practicalneurology.com/2011/04/neurotoxin-therapy-a-closer-look-at-the-fouroptions/. Accessed August 20, 2015.

11. Botox (onabotulinumtoxinA) prescribing information and medication guide. Allergan. Revised August 2015. Available at: http://www.allergan. com/assets/pdf/botox_pi.pdf. Accessed August 20, 2015.

12. Dysport (abobotulinumtoxinA) prescribing information and medication guide. Ipsen Biopharm Ltd. Revised September 2013. Available at: http:// www.dysport.com/hcp/PDFs/Dysport_Patients_PI_Sept2013.pdf. Accessed August 20, 2015.

13. Panjwani N, O'Keefe R, Pickett A. Biochemical, functional and potency characteristics of type A toxin in clinical use. The Botulinum J. 2008;1(1):153-66. 14. Yun JY, Kim JW, Kim HT, et al. Dysport and Botox at a ratio of 2.5:1 units in cervical dystonia: a double-blind, randomized study. Mov Disord. 2015;30(2):206-13.

15. Odergren T, Hjaltason H, Kaakkola S, et al. A double blind, randomised, parallel group study to investigate the dose equivalence of Dysport and Botox in the treatment of cervical dystonia. J Neurol Neurosurg Psychiatry. 1998;64(1):6-12.

16. Ranoux D, Gury C, Fondarai J, Mas JL, Zuber M. Respective potencies of Botox and Dysport: a double blind, randomised, crossover study in cervical dystonia. J Neurol Neurosurg Psychiatry. 2002;72(4):459-62.

17. Rystedt A, Nyholm D, Naver H. Clinical experience of dose conversion ratios between 2 botulinum toxin products in the treatment of cervical dystonia. Clin Neuropharmacol. 2012;35(6):278-82.

18. Gill CE, Manus ND, Pelster MW, et al. Continuation of long-term care for cervical dystonia at an academic movement disorders clinic. Toxins (Basel). 2013;5(4):776-83.

19. Comella C, Bhatia K. An international survey of patients with cervical dystonia. J Neurol. 2015;262(4):837-48.

20. American Medical Association. ICD-9-CM 2014 Physician Codebook. Chicago: AMA; 2014.

21. Jankovic J, Orman J. Botulinum A toxin for cranial-cervical dystonia: a double-blind, placebo-controlled study. Neurology. 1987;37(4):616-23.

22. American Medical Association. CPT 2013 Standard Edition (Current Procedural Terminology). Chicago: AMA; 2013.

23. Truong D, Trosch RM, Comella CL, et al. ANCHOR-CD

(AbobotulinumtoxinA Neurotoxin Clinical and Health Economics Outcomes Registry in Cervical Dystonia): baseline data and cycle one efficacy data. Poster presented at: American Academy of Neurology; May 3, 2014; Philadelphia, PA.

24. Molho ES, Agarwal N, Regan K, Higgins DS, Factor SA. Effect of cervical dystonia on employment: a retrospective analysis of the ability of treatment to restore premorbid employment status. Mov Disord. 2009;24(9):1384-87.

25. Brefel-Courbon C, Simonetta-Moreau M, More C, et al. A pharmacoeconomic evaluation of botulinum toxin in the treatment of spasmodic torticollis. Clin Neuropharmacol. 2000;23(4):203-07.

26. Jankovic J, Leder S, Warner D, Schwartz K. Cervical dystonia: clinical findings and associated movement disorders. Neurology. 1991;41(7):1088-91.

27. Wisconsin Physician Services. Michigan Medicare J8 MAC Part B. Botulinum Toxin Type A \& B Billing and Coding Guidelines. Available at: http://downloads.cms.gov/medicare-coverage-database/lcd_attachments/28555_80/L28555_INJ018_BCG.pdf. Accessed September 8, 2015.

28. Centers for Medicare and Medicaid Services. Medicare Claims Processing Manual. CMS Pub. Chap. 17, Sec. 40 (Rev. 1962, April 30, 2010). Available at: https://www.cms.gov/Regulations-and-Guidance/Guidance/ Manuals/downloads/clm104c17.pdf. Accessed September 8, 2015. 